\title{
ST Segment Elevation Besides Acute Myocardial Infarction
}

\section{ZAHID ALAM ${ }^{1}$, ROWSANARA ${ }^{2}$, MOHAMMAD FERDOUS UR RAHAMAN ${ }^{3}$, HAFEZ MOHAMMAD NAZMUL} AHSAN $^{4}$, MOHAMMAD SALMAN $^{5}$, JANNATARA SHEFA ${ }^{6}$

${ }^{1}$ Department of Cardiology, BIRDEM Hospital, Dhaka, ${ }^{2}$ Department of Medicine, Green Life Medical College and Hospital, Dhaka, 3Department of Medicine, Bangabandhu Sheikh Mujib Medical University, Dhaka, ${ }^{4}$ Department of Medicine, Shahid Suhrawardi Medical College, Dhaka, ${ }^{5}$ Department of Cardiology Anwer Khan Modern Medical College, Dhaka, ${ }^{6} \mathrm{department}$ of Community Medicine, Monno Medical College, Manikgonj

Address for correspondence: Dr. Md. Zahid Alam, Assistant Professor, Dept of Cardiology, BIRDEM Hospital, Shaghbag, Dhaka-1000, email: ilazybear@yahoo.com

\begin{abstract}
:
ST segment elevation (STE) in electrocardiography (ECG) commonly denotes acute myocardial infarction (AMI) ${ }^{1,2}$. As AMI needs prompt diagnosis and specific treatment like thrombolysis, anticoagulation or primary percutaneous coronary intervention (PCI) which significantly improve outcome ${ }^{1}$, recognition of other conditions where STE also occurs are equally important to avoid potential hazards. This review points out to such conditions of ECG tracing.
\end{abstract}

Key words: ST, elevation, myocardial infraction

\section{Normal variant of ST segment elevation}

STE is commonly observed in the electrocardiogram of normal persons (figure 1). A study done on 45 normal volunteers suggest that standard precordial leads do not accurately predict maximal torso potentials during the ST segment, thus STE may commonly be seen without acute myocardial infarction ${ }^{3}$. Another study conducted on 6014 healthy men in the U.S. Air Force who were 16 to 58 years old, 91\% had STE of 1-3 $\mathrm{mm}$ in one or more precordial leads ${ }^{4}$. Other study by Surawicz and Parikh on 529 males and 544 females, age 5 to 96 years, showed variation of

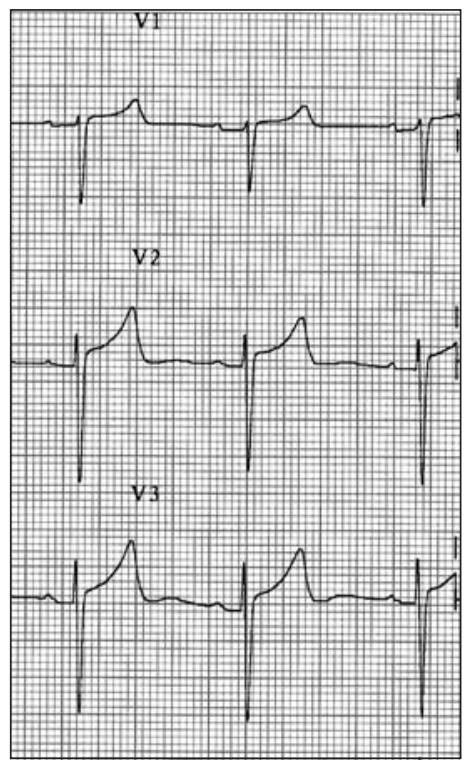

Fig.-1: ST segment elevation (in V2 \& V3) in a normal healthy person
STE between normal male and female that is, prevalence of STE of at least $1 \mathrm{~mm}$ in one or more of leads $\mathrm{V} 1$ through $\mathrm{V} 4$ was $93 \%$ in the men who were 17 to 24 years old ${ }^{5}$. According to these studies, it is now established that the main feature of the male pattern in electrocardiograms (ECG) is ST elevation at the J-point of $=0.1 \mathrm{mV}$ in at least one of the leads V1-V4 with concave upward ST-segments and the prevalence of the male pattern in ECG of healthy male (mostly Caucasians or Blacks) who were 16-58 years old was high (85\%) $)^{4,5}$. Much higher prevalence was observed in a recent study in Hong Kong (on 202 apparently healthy Chinese adult males, aged $20-54$ years) which was $95.5 \%{ }^{6}$.

\section{Early repolarization syndrome}

The early repolarization syndrome (ERS) is a common electrocardiographic variant characterized by J-point elevation manifested either as QRS slurring (at the transition from the QRS segment to the ST segment) or notching (a positive defection inscribed on terminal $\mathrm{S}$ wave), STE with upper concavity and prominent $\mathrm{T}$ waves in at least 2 contiguous leads ${ }^{7-10}$. In most of the studies elevation of the J point and/or ST- segment from the baseline by at least $0.1 \mathrm{mV}$ was considered definitive of $\mathrm{ER}^{9,11}$ (figure 2).

ERS is found in approximately $1 \%$ to $2 \%$ of the young adult population and in up to $13 \%$ to $48 \%$ of patients presenting with chest pain in the emergency rooms and coronary care units. It generally occurs in the absence of myocardial disease ${ }^{12,13}$. Its predominance is in young black males and shows disproportionate infrequency in white females ${ }^{14}$. This syndrome is common in people under the age of 30 years old and shows decreasing incidence with 


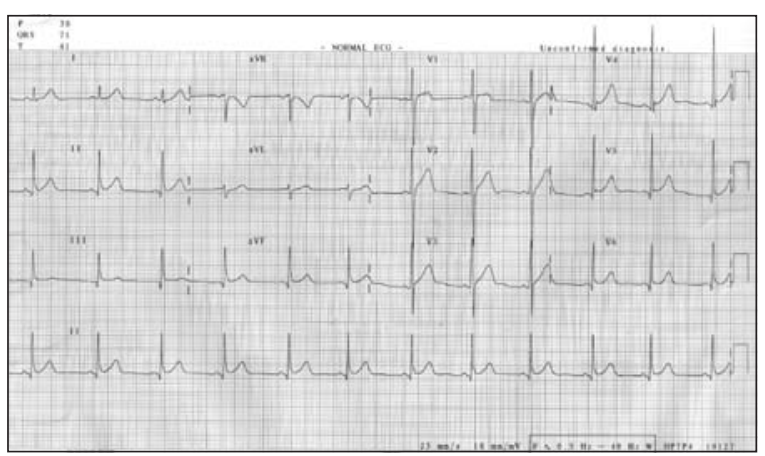

Fig.-2: Early repolarization syndrome

advancing age ${ }^{15}$. It is predominant in more athletically active people and more infrequent in sedentary ${ }^{16}$. There is a higher prevalence of ERS in individuals with spinal cord injury at levels of injury that can disrupt central sympathetic command of the heart (at the C5 - C6 levels) with high vagal tone and loss of sympathetic tone ${ }^{17}$.

\section{Acute pericarditis}

Acute pericarditis is a diffuse inflammation of the pericardial sac and superficial epicardium from a multitude of infectious and inflammatory processes. This inflammation results in a current of myocardial injury resulting from the epicardial irritation manifested by a number of electrocardiographic findings. Classically, the electrocardiographic changes have been described as an evolution through several distinct stages involving STE with PR segment depression, normalization of the ST segment abnormality with $\mathrm{T}$ wave inversion, and eventual normalization of the electrocardiogram over a period of days to several weeks ${ }^{18}$.

The changes in initial stage may be confused with findings of MI or early repolarization; old ECGs help differentiate among these conditions. It is important to remember that no PR-segment depression occurs in $\mathrm{MI}$ and no reciprocal changes or Q waves are found in the 12-lead ECG during acute pericarditis (figure 3 ), which is an important feature in distinguishing acute pericarditis from acute $\mathrm{MI}^{19-22}$. In addition, the STE in acute infarction is upwardly convex in concordant leads, and Q waves often appear. The most reliable differential finding in the ECG is the ratio of the magnitude of the STE to the T-wave amplitude in the V6 lead; acute pericarditis is more likely when the ratio is greater than $0.25^{23,24}$.

\section{Left ventricular aneurysm}

The persistence of the typical pattern of the fully evolved phase of myocardial infarction-Q wave, STE and inverted $\mathrm{T}$ wave - for 3 months or longer after the acute attack

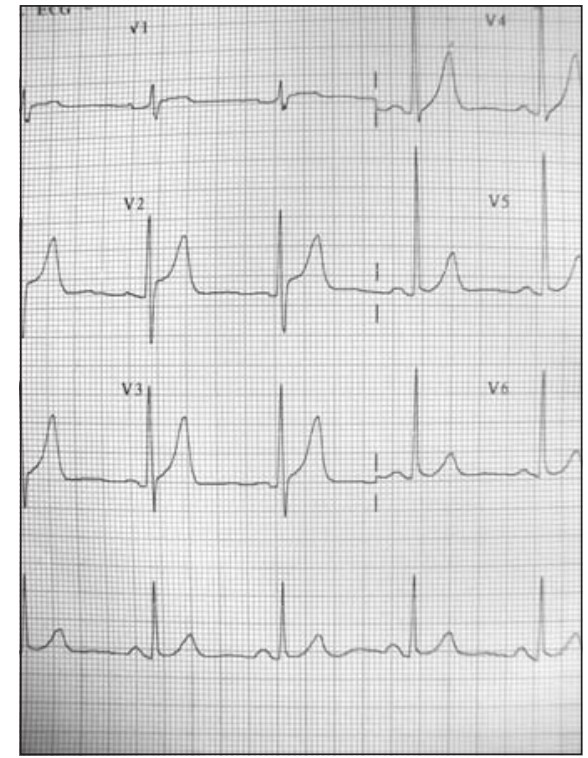

Fig.-3: ECG from a patient with acute pericarditis. Note the PR depression with mild ST elevation

suggests the development of a ventricular aneurysm ${ }^{25}$. Left ventricular aneurysm (LVA), also described as dyskinetic left ventricular segment, is defined as a localized area of infarcted myocardium that bulges outward during both systole and diastole. LVAs most often are noted after large anterior wall events but may also be encountered status after inferior and posterior wall injuries. In most cases, LVA is manifested in ECG by varying degrees of STE, which may be difficult to distinguish from ST segment changes caused by acute myocardial infarction. The STE is generally associated with well-developed, completed Q waves in the anterior precordial leads, and there will not be reciprocal ST depression in the contralateral leads ${ }^{26}$.

Vasilomanolakis et al reviewed ECG of 77 patients underwent left ventricular aneurysmectomy and observed, post-operatively, significant decreases in ST segment elevation ( $p<0.001)$, with anterior $(p<0.03)$ and inferior $R$ wave heights ( $\mathrm{p}<0.002)$. In addition, abnormal $\mathrm{Q}$ waves disappeared in $50 \%$ of patients. This indicates that LVA affects ventricular repolarization as evidenced by a significant decrease in ST elevation and left ventricular aneurysmectomy affects ventricular depolarization as evidenced by a significant loss of $\mathrm{R}$ wave height and changes in infarct pattern ${ }^{27}$.

\section{Left bundle branch block}

Left bundle branch block (LBBB) is the result of the delay or interruption of conduction within the left bundle branch. The ST segment and $\mathrm{T}$ wave are opposite in direction to the terminal QRS deflection. These are secondary 
phenomena, ie they occur secondarily to the abnormal intraventricular conduction and do not indicate primary ST segment and T wave abnormality. In leads oriented to the right ventricle (V1 and V2) the ST segment is elevated and often minimally concave-upward and the $\mathrm{T}$ wave is asymmetrical. In leads oriented to the left ventricle (V5 and V6) the ST segment is depressed and often minimally convex-upward and the $\mathrm{T}$ wave is inverted with a blunt nadir 28 (figure 4).

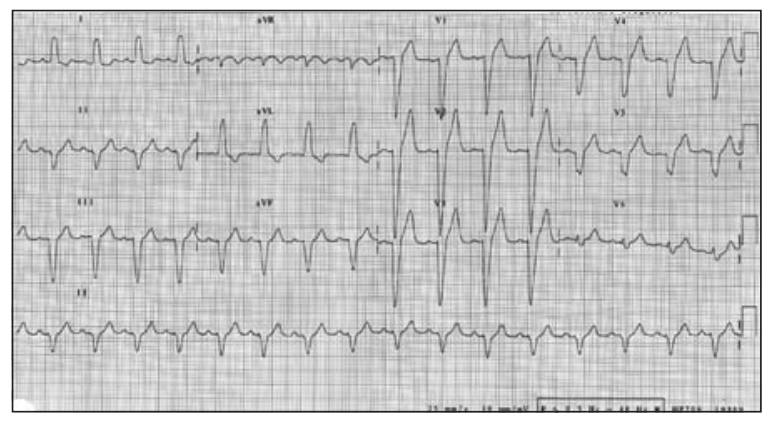

Fig.-4: Left bundle branch block

Making the diagnosis of AMI in the presence of LBBB can be problematic. However, the secondary ST-T changes in LBBB described above are shifted to the opposite direction from the major component of the QRS complex (i.e., discordant). When these changes are concordant, they are specific for acute myocardial infarction ${ }^{29,30}$. Another criterion that has been proposed for recognizing an associated anteroseptal infarct is STsegment elevation of $5 \mathrm{~mm}$ or more ${ }^{29}$.

\section{Prinzmetal angina}

Prinzmetal angina is used to describe recurrent episodes of ischaemic cardiac pain at rest accompanied by reversible STE without cardiac enzyme elevation. This ECG change reflects transmural ischaemia and indicates total or subtotal obstruction to blood flow through a major coronary artery. Although STE is a common finding during spasm, ST-segment depression and T-wave changes may also be observed during different ischaemic episodes in the same patient. These latter changes reflect lesser degrees of ischaemia suggesting varying severity of spasm at the same site or varying extent of involvement of the coronary artery tree by spasm ${ }^{31,32}$. The spasms are most commonly focal and can occur simultaneously in more than one site. Even coronary segments that are apparently normal at the coronary angiography, often show evidence of mural atherosclerosis at the intravascular ultrasound. This can result in localized endothelial dysfunction and coronary spasm ${ }^{33,34}$.
The key to the diagnosis of prinzmetal angina is the documentation of the STE in a patient during transient chest discomfort (which usually occurs at rest, typically in the early morning hours, and is non-reproducible during exercise) and that resolves when the chest discomfort abates $^{32,35}$.

\section{Left ventricular hypertrophy}

Left ventricular hypertrophy (LVH) sometimes show STE in the right oriented leads with a slight upward concavity ${ }^{36}$. Brady et al conducted a study on 202 patients who presented with chest pain and STE showed 31 (15\%) patients had STE acute myocardial infarction (AMI) as the final hospital diagnosis which caused the STE; 171 (85\%) patients with STE had non-AMI diagnosis responsible for the STE, including LVH 51 (25\%), LBBB 31 (15\%), benign early repolarization (BER) 25 (12\%), right bundle branch block 10 (5\%), nonspecific bundle branch block 10 (5\%), left ventricular aneurysm 5 (3\%), acute pericarditis 2 (1\%), ventricular paced rhythm 2 (1\%), and undefined ST segment elevation $35(17 \%)^{37}$.

\section{Brugada syndrome}

Brugada syndrome (figure 5) is characterized by a specific electrocardiographic pattern in the right precordial leads and susceptibility to ventricular arrhythmias and sudden death $^{38}$. Three different ECG patterns were described: a) type I, characterized by a coved-type ST-segment elevation eŠ 2 mm in more than one right precordial lead (V1-V3),

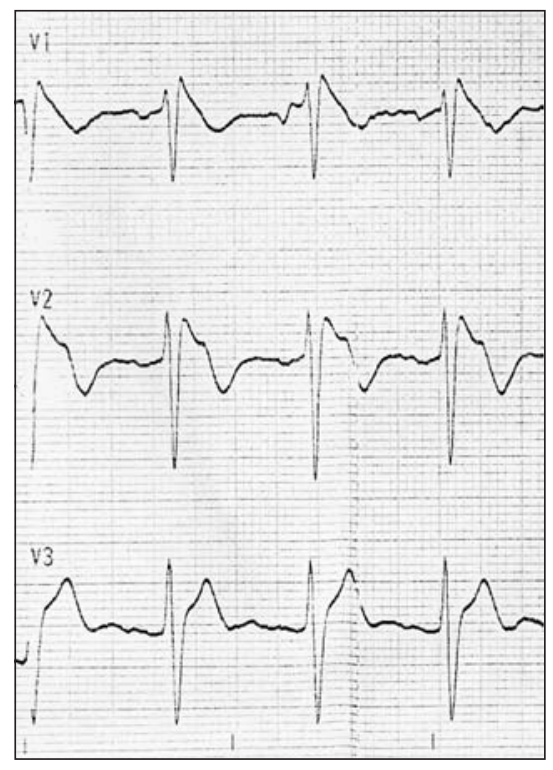

Fig.-5: Brugada syndrome (type I). Note the characteristic coved-type ST-segment elevation in lead $V 1-V$ followed by negative $T$ waves 
followed by negative T waves; b) type II, characterized by ST-segment elevation eŠ $2 \mathrm{~mm}$ in right precordial leads followed by positive or biphasic $\mathrm{T}$ waves, resulting in a saddleback configuration; and c) type III, defined as any of the 2 previous types if ST-segment elevation is dŠ 1 $\mathrm{mm}^{39,40}$. Although the 3 patterns can be observed in Brugada syndrome, and even in the same patient at different times, type I is the only one that is considered diagnostic of the disease ${ }^{39}$.

Patients with Brugada syndrome usually remain asymptomatic. Nevertheless, it has been reported that $17 \%$ to $42 \%$ of them present syncope or SCD as a consequence of a ventricular arrhythmia at some time during their lives ${ }^{41-}$ 44. An ICD is the only treatment with demonstrated efficacy in Brugada syndrome. ICD implantation is recommended for all patients who have already had symptoms and for asymptomatic patients in whom the EPS induces ventricular arrhythmias, especially if they present a spontaneous type I ECG pattern. In the asymptomatic patients, without a family history of SCD and whose type I ECG pattern is only documented after the administration of sodium channel blockers, periodic follow up is recommended without the need of an EPS for risk stratification ${ }^{40}$.

\section{Pulmonary embolism}

Pulmonary embolism is a common cardiovascular emergency, but it is still often misdiagnosed due to its unspecific clinical symptoms, so various models have been developed to help its diagnosis ${ }^{45}$. ECG changes are very unspecific and range from most common sinus tachycardia, rightward shift in QRS axis, complete or incomplete right bundle branch block, precordial T wave inversion, S1Q3T3 pattern and more uncommon ST segment elevation ${ }^{46,47}$. A few case reports describe ECG presentation of pulmonary embolism as STE in precordial leads, but exact mechanism is still unclear ${ }^{47-49}$.

Electrical cardioversion: Transient elevation of the ST segment after electrical cardioversion has been very well reported in the literature, with an incidence as high as $16 \%$. The mechanism of these ST-segment elevations is not clear ${ }^{50}$. Two main explanations have been suggested: myocardial injury or coronary vasospasm ${ }^{51}$.

Hypercalcemia: Severe hypercalcaemia provoking ECG changes mimicking acute myocardial infarction is infrequently reported. STE is usually seen in leads V1$\mathrm{V}^{52}$. Nishi et al reported a case of hypercalcemia presented with STE which resolved after correction of hypercalcemia ${ }^{53}$. The ECG changes of severe hypercalcemia (>14 mg/dl) can mimic acute myocardial infarction in two ways: First, calcium shortens phase 2 of the cardiac muscle action potential, leading to shortening of the ST segment. Thus the shortening of QaTc seen in hypercalcemia produces a high takeoff of the ST segment simulating acute myocardial ischemia. As the ST segment is difficult to measure however, QT intervals have been used to evaluate the ECG effects of hypercalcemia. Secondly,flattened or biphasic $\mathrm{T}$ waves are prominent in moderate to severe hypercalcemia ${ }^{54,55}$.

In a situation in which emergency calcium assays are not available, the ability to diagnose hypercalcemia from the ECG is valuable, and a QTc interval of 0.27 second or less is a reliable indicator in differentiating hypercalcemia from true myocardial ischemia ${ }^{56}$.

\section{Hypertrophic cardiomyopathy}

Hypertrophic cardiomyopathy (HCM) is a primary disease of myocardium resulting in myocardial hypertrophy without any inciting pressure or volume overload. The electrocardiographic features of hypertrophic cardiomyopathy are numerous, including ST segment elevation that may simulate other STE conditions. Several cases of HCM are reported having STE in their ECGs without $\mathrm{AMI}^{57,58}$. Chronic ST segment elevation has been occasionally described in patients with HCM complicated with apical necrosis and aneurysm formation, but not in uncomplicated cases of apical $\mathrm{HCM}^{58}$.

\section{Sickle cell anaemia}

Sickle cell anaemia is associated with significant electrocardiographic abnormalities. A descriptive cross sectional study was done on 60 sickle cell anaemia patients by Oguanobi et al showed that non specific STE of $2 \mathrm{~mm}$ and T- wave inversion in the right precordial leads occurred in $10 \%$ and $13.33 \%$ of the patients respectively. Although it has been suggested that the ST - T wave abnormality might be an index of myocardial ischaemia, no clear evidence of myocardial infarction was demonstrated by this study and isolated cases of ST segment and T-wave changes were observed and there were no significant Qwave abnormality were noted ${ }^{59}$. Aluko ${ }^{60}$ and Sergeant ${ }^{61}$ found ST segment and T-wave changes in 9\% and 5\% respectively of adult steady state patients. Racial differences may explain the slightly higher values in the study of Oguanobi et al when compared with the findings of Sergeant on Jamaican patients ${ }^{61}$.

\section{Conclusion:}

Though STE most commonly is due to AMI, many other conditions can mimic this important electrocardiographic 
feature. In patients who present with chest pain, STE is likely to be cardiac in origin and prompt recognition and treatment improves outcomes. However, unnecessary treatment with thrombolytic therapy or anticoagulation can be much harmful, and in patients who are at low risk of cardiac disease other causes must be ruled out. Pattern of STE in AMI is commonly convexity upward but in nonAMI it is usually somewhat depressed or concave along the ascending limb of the $T$ wave $^{2}$. Still, if confused, it is mandatory to confirm AMI by cardiac markers, echocardiography or coronary angiogram to avoid case fatality.

\section{References:}

1. Newby DE, Grubb NR, Bradbury A. Cardiovascular disease. In: Colledge NR, Walker BR, Ralston SH, editors. Davidson's Principles \& Practice of Medicine.21 ${ }^{\text {st }}$ ed. Edinburgh:Churchill Livingstone; 2010. P. 590-5.

2. Schamroth L. Myocardial infarction. In. Schamroth C, editor. An introduction to Electro Cardiography. $7^{\text {th }}$ ed. London: Blackwell Science;1990. P.140.

3. Mirvis DM. Evaluation of normal variations in S-T segment patterns by body surface isopotential mapping: S-T segment elevation in absence of heart disease. Am J Cardiol 1982;50(1):122-8.

4. Hiss RG, Lamb LE, Allen MF. Electrocardiographic findings in 67,375 asymptomatic subjects. Am J Cardiol 1960;6:20031.

5. Surawicz B, Parikh SR. Prevalence of male and female patterns of early ventricular repolarization in the normal ECG of males and females from childhood to old age. J Am Coll Cardiol 2002;40:1870-6.

6. Ho J, Lee KH, Tsui CSY, Ko HF, Lit CH. The prevalence of the male pattern in electrocardiograms of healthy Chinese adult males in Hong Kong. Hong Kong $\mathrm{j}$ emerg med 2005;12(4):198-205.

7. Tikkanen JT, Anttonen O, Junttila MJ, Aro AL, Kerola T, Rissanen HA, et al. Long-term outcome associated with early repolarization on electrocardiography. N Engl J Med 2009;361: $2529-37$.

8. Mehta M, Jain AC, Mehta A. Early repolarization. Clin Cardiol 1999; 22: 59 - 65 .

9. Huikuri HV, Castellanos A, Myerburg RJ. Sudden death due to cardiac arrhythmias. N Engl J Med 2001;345: 1473 - 82.

10. Haïssaguerre M, Derval N, Sacher F, Jesel L, Deisenhofer I, de Roy L, et al. Sudden cardiac arrest associated with early repolarization. N Engl J Med 2008; 358:2016 - 23.

11. Gaita F, Giustetto C, Bianchi F, Wolpert C, Schimpf R, Riccardi R, et al. Short QT syndrome: A familial cause of sudden death. Circulation 2003;108: 965 - 70.

12. Hasbak P, Engelmann MD. Early repolarization. ST-segment elevation as normal electrocardiographic variant. Ugeskr Laeger 2000;162:5928-9.
13. Brady WJ, Chan TC. Electrocardiographic manifestations: benign early repolarization. J Emerg Med 1999;17:473-8.

14. Spratt KA, Borans SM, Michelson EL. Early repolarization: normalization of the electrocardiogram with exercise as a clinically useful diagnostic feature. J Invasive Cardiol 1995; 7:238-42.

15. Riera ARP, Uchida AH, Schapachnik E, Dubner S, Zhang L, Filho CF, et al. Early repolarization variant: Epidemiological aspects, mechanism, and differential diagnosis. Cardiol J 2008;15(1):4-16.

16. Klatsky AL, Oehm R, Cooper RA, Udaltsova N, Armstrong MA. The early repolarization normal variant electrocardiogram: correlates and consequences. Am J Med, 2003; 115: 171-7.

17. Marcus RR, Kalisetti D, Raxwal V et al. Early repolarization in patients with spinal cord injury: Prevalence and clinical significance. J Spinal Cord Med 2002; 25: 33-8.

18. Chan TC, Brady WJ, Pollack M. Electrocardiographic manifestations: acute myopericarditis. J Emerg Med 1999;17(5):865-72.

19. Tingle LE, Molina D, Calvert CW. Acute pericarditis. Am Fam Physician 2007;76:1509-14.

20. Permanyer-Miralda G. Acute pericardial disease: approach to the aetiologic diagnosis. Heart 2004;90:252-4.

21. Aikat S, Ghaffari S. A review of pericardial diseases: clinical, ECG and hemodynamic features and management. Cleve Clin J Med 2000;67:903-14.

22. Surawicz B, Lasseter KC. Electrocardiogram in pericarditis. Am J Cardiol 1970;26:471-4.

23. Spodick DH. Electrocardiogram in acute pericarditis. Distribution of morphologic and axial changes by stages. Am J Cardiol 1974;33:470-4.

24. Ginzton LE, Laks MM. The differential diagnosis of acute pericarditis from the normal variant: new electrocardiographic criteria. Circulation 1982;65:1004-9.

25. Schamroth L. Myocardial infarction. In. Schamroth C, editor. An introduction to Electro Cardiography. $7^{\text {th }}$ ed. London: Blackwell Science;1990. P.155.

26. Engel J, Brady WJ, Mattu A, Perron AD. Electrocardiographic ST segment elevation: left ventricular aneurysm. Am J Emerg Med 2002;20(3):238-42.

27. Vasilomanolakis EC, Ruggie N, Codini M, Messer JV, Denes P. The effect of left ventricular aneurysmectomy on the electrocardiogram: a study of 77 patients and review of the literature. J Electrocardiol 1982;15(2):173-9.

28. Schamroth L. Left bundle branch block. In. Schamroth C, editor. An introduction to Electro Cardiography. $7^{\text {th }}$ ed. London: Blackwell Science;1990. P.99-104.

29. Sgarbossa EB, Pinski SL, Barbagelata A, Underwood DA, Gates KB, Topol EJ, et al. Electrocardiographic diagnosis of evolving acute myocardial infarction in the presence of left bundle-branch block. N Engl J Med 1996;334:481-7. 
30. Hands ME, Cook EF, Stone PH, Muller JE, Hartwell T, Sobel $\mathrm{BE}$, et al. Electrocardiographic diagnosis of myocardial infarction in the presence of complete left bundle branch block. Am Heart J 1988;116:23-31.

31. Rrichmond D. Coronary artery spasm: a review. J Royal Soc Med 1980;73:570-5.

32. Tada Y, Keane D, Serruys PW. Fluctuation of spastic location in patients with vasospastic angina: a quantitative angiographic study. J Am Coll Cardiol 1995;26:1606-14.

33. Yasue H, Horio Y, Nakamura N, Fuji H, Imoto N, Sonoda R. Induction of coronary artery spasm by acetylcholine in patients with variant angina: possible role of the parasympathetic nervous system in the pathogenesis of coronary artery spasm. Circulation 1986;74:955-63.

34. Matsuda Y, Ozaki M, Ogawa H, Naito H, Yoshino K, Katayama K, et al. Coronary arteriography and left ventriculography during spontaneous and exercise-induced ST segment elevation in patients with variant angina. Am Heart J 1983;106:509-15.

35. Maseri A, Severi S, Nes MD, Denes M, L’Abbate A, Cheirchia $S$, et al. "Variant" angina: one aspect of a continuous spectrum of vasospastic myocardial ischemia: pathogenetic mechanisms, estimated incidence and clinical and coronary arteriographic findings in 138 patients. Am J Cardiol 1978;42:1019-35.

36. Schamroth L. Ventricular hypertrophy. In. Schamroth C, editor. An introduction to Electro Cardiography. $7^{\text {th }}$ ed. London: Blackwell Science;1990. P.70-1.

37. Brady WJ, Perron AD, Martin ML, Beagle C, Aufderheide TP. Cause of ST segment abnormality in ED chest pain patients. Am J Emerg Med 2001;19(1):25-8.

38. Benito B, Brugada J, Brugada R, Brugada P. Brugada Syndrome. Rev Esp Cardiol 2009;62(11):1297-315.

39. Wilde AAM, Antzelevitch C, Borggrefe M, Brugada J, Brugada $\mathrm{R}$, Brugada $\mathrm{P}$, et al. Proposed diagnostic criteria for the Brugada syndrome. Eur Heart J. 2002;23:1648-54.

40. Antzelevitch C, Brugada P, Borggrefe M, Brugada J, Brugada R, Corrado D, et al. Brugada syndrome: Report of the Second Consensus Conference: Endorsed by the Heart Rhythm Society and the European Heart Rhythm Association. Circulation 2005;111:659-70.

41. Brugada J, Brugada R, Antzelevitch C, Towbin J, Nademanee K, Brugada P. Long-term follow-up of individuals with the electrocardiographic pattern of right bundle-branch block and ST-segment elevation in precordial leads V1 to V3. Circulation 2002;105:73-8.

42. Priori SG, Napolitano C, Gasparini M, Pappone C, Bella PD, Umberto G, et al. Natural history of Brugada syndrome: insights for risk stratification and management. Circulation 2002;105:1342-7.

43. Brugada J, Brugada R, Brugada P. Determinants of sudden cardiac death in individuals with the electrocardiographic pattern of Brugada syndrome and no previous cardiac arrest. Circulation 2003;108:3092-6.
44. Eckardt L, Probst V, Smits JPP, Bahr ES, Wolpert C, Schimpf $\mathrm{R}$, et al. Long-term prognosis of individuals with right precordial ST-segment elevation Brugada syndrome. Circulation 2005;111:257-63.

45. Miniati M, Monti S, Bottai M: A structured clinical model for predicting the probability of pulmonary embolism. Am J Med 2003, 114(3):173-9.

46. Pollack ML: ECG manifestations of selected extracardiac diseases. Emerg Med Clin North Am 2006;24(1):133-43.

47. Falterman TJ, Martinez JA, Daberkow D, Weiss LD: Pulmonary embolism with ST segment elevation in leads V1 to V4: case report and review of the literature regarding electrocardiographic changes in acute pulmonary embolism. J Emerg Med 2001;21(3):255-61.

48. Wilson GT, Schaller FA: Pulmonary embolism mimicking anteroseptal acute myocardial infarction. J Am Osteopath Assoc 2008;108(7):344-9.

49. Cheng TO: Mechanism of ST-elevation in precordial leads $\mathrm{V}(1)-\mathrm{V}(4)$ in acute pulmonary embolism. Int $\mathrm{J}$ Cardiol 2009;136(3):251-2.

50. Shafiq Q, Bashir R. ST-Segment Elevations Secondary to Electrical Cardioversion. Circulation 2007;116;519-20.

51. Cantor A, Stein B, Keynan A. "Intermittent" and transient ST-segment elevation following direct current cardioversion. Int J Cardiol 1988;20(3):403-5.

52. Wesson LC, Suresh V, Parry RG. Severe hypercalcaem mimicking acute myocardial infarction. Clinical Medicine 2009;9(2):186-7.

53. Nishi SP, Barbagelata NA, Atar S, Birnbaum Y, Tuero E. Hypercalcemia-induced ST-segment elevation mimicking acute myocardial infarction. J Electrocardiol 2006;39(3):298-300.

54. Douglas PS, Carmichael KA, Palevsky PM. Extreme hypercalcemia and electrocardiographic changes. AmJ Cardiol 1984;54:674-5.

55. Ahmed R, Yano K, Mitsuoka T, Ikeda S, Ichimaru M, Hashiba $\mathrm{K}$. Changes in $\mathrm{T}$ wave morphology during hypercalcemia and its relation to the severity of hypercalcemia. J Electrocardiol 1989;22:125-32.

56. NierenbergDW, Ransil BJ. Q-aTc interval as a clinical indicator of hypercalcemia. Am J Cardiol 1979;44:243-8.

57. Khan IA, Ajatta FO, Ansari AW.Persistent ST segment elevation: a new ECG finding in hypertrophic cardiomyopathy. Am J Emerg Med 1999;17(3):296-9.

58. Penas Lado M, Mosquera Pérez I, Bouzas Zubeldía B, Vázquez Rodríguez JM, Castro Beiras A. The electrocardiogram in apical hypertrophic myocardiopathy. A case report with unique manifestations. Rev Esp Cardiol 1999;52(12):1148-50.

59. Oguanobi NI, Onwubere BJC, Ike SO, Anisiuba BC, Ejim EC, Ibegbulam OG. Electocardiographic findings in adult Nigerians with sickle cell anaemia. African Health Sciences 2010;10(3): $235-41$.

60. Aluko OA. The heart in sickle cell disease. FMCP Dissertation. National Postgraduate Medical College of Nigeria. 1985.

61. Serjeant GR. Sickle cell disease. 2nd ed. New York :Oxford;1992. P.129-38. 